Zagazig Veterinary Journal

Volume 44, Number 2, p 149-155, September, 2016

OFaculty of Veterinary Medicine, Zagazig University, 44511, Egypt

DOI: 10.21608/zvjz.2016.7857

\title{
Efficacy of an Experimental Combined Inactivated Salmonella Typhimurium and Paramyxovirus Vaccine in Pigeons \\ Afaf A. Khedr ${ }^{1}$, Anhar A. Abdel Latef ${ }^{1 *}$, Mahmoud L. Sayed ${ }^{1}$, Mohamed A. Abdrabo ${ }^{1}$, Nourhan \\ $\mathrm{Nagy}^{1}$, Amina A. Radwan ${ }^{1}$ and Samah E. Abo Dalal ${ }^{2}$ \\ ${ }^{1}$ Central Laboratory for Evaluation of Veterinary Biologics, Cairo, Egypt \\ ${ }^{2}$ Veterinary Serum and Vaccine Research Institute, Abbasia, Cairo, Egypt
}

Article History: Received: 8/9/2016 Received in revised form: 18/9/2016 Accepted: 25/9/2016

\begin{abstract}
Pigeon paramyxovirus type 1 (PPMV-1) and salmonellosis are two of the major health problems that affect pigeons worldwide. Immuno-protection of pigeons against PPMV-1 infection and salmonellosis is a very important preventive measure. In the present work, a combined inactivated montanide ISA-206 oil adjuvanted vaccine of local isolates of PPMV-1 and $S$. Typhimurium was prepared. Quality control assessment of such preparation revealed that it is free from foreign contaminants, safe and immunogenic. The sero-evaluation using microplate agglutination test revealed that the humoral immune response developed against $S$. Typhimurium in the vaccinated pigeons reached 64 three weeks post $1^{\text {st }}$ dose and reached its maximum value 256 two weeks post boostering. Results of HI test showed that the vaccine induced detectable humoral immune response to PPMV-1 expressed by marked increased HI antibody titer till the end of the experiment $\left(8.0 \log _{2}\right)$. The vaccination-challenge assay with the virulent strain of PPMV-1 with $10^{6} \mathrm{EID}_{50} / \mathrm{mL}$ showed $100 \%$ protection in vaccinated group (Ia). While, the virulent $S$. Typhimurium organism with $5 \times 10^{7} \mathrm{CFU} /$ bird showed $90 \%$ protection in vaccinated birds. The unvaccinated control group showed $10 \%$ and $20 \%$ protection against both virulent PPMV-1 and S. Typhimurium, respectively. In conclusion, this vaccine could be recommended as safe, potent and could be useful when used for protection against PPMV-1 and $S$. Typhimurium under field condition.
\end{abstract}

Keywords: Salmonellosis, PPMV-1, Pigeons, Vaccine

\section{Introduction}

Pigeons are known to be susceptible to infection with avian paramyxovirus serotype-1 (APMV-1) which includes Newcastle disease virus (NDV) [1]. The occurrence of paramyxovirus-1 (PMV-1) in pigeons has already been reported primarily in racing pigeons, and was spreading to wild birds and poultry, which is caused by the virulent APMV1 virus [2-7]. The virus is antigenically and genetically distinguishable from other APMV-1 viruses and has been termed as pigeon paramyxovirus type 1 (PPMV-1) [8]. The virus spread across Europe and the world during 1981-1983 causing respiratory and neural symptoms in pigeons [9]. The most common neural signs that occur during infections with PPMV-1 include head and neck twists (torticollis), imbalance, paralysis of wings and legs or difficulties in food intake [10]. Infected birds sometimes have watery or bloody diarrhea.

The incidence of the disease varies from 30 to $70 \%$, with mortality not exceeding $10 \%$. While in case of association with bacterial or parasitic infections, mortality may reach more than $30 \%$. In Egypt, PPMV-1 is isolated from outbreaks affecting pigeons in several occasions [4,5]. Trials for preparation of inactivated vaccine from a local strain were made and a protection percent of $80 \%$, with high level of immune response lasting for five months were reported [11,12].

Salmonellosis is a major bacterial disease problem affecting pigeons caused by $S$. Typhimurium and $S$. Enteritidis. High rate of mortality in the first day of life of pigeon 
squabs is a sign of infection with Salmonella species, while, the disease progresses very slowly in adult pigeons with symptoms of diarrhea, anorexia, and polydipsia. Pigeons start losing weight and show arthritis or even paralysis [13]. Spleen and liver enlarge in size and nodules in the internal organs can occur.

Concerning the public health, pigeons play an important role in the transmission of diseases that affect humans and domestic animals [14]. Several authors have isolated Salmonella spp. in the feces, cloacal swabs and organs of pigeons [15-19]. In Egypt Ammar et al., [20] isolated Salmonella spp. from 5\% of squabs and from $3.5 \%$ of adult pigeons.

Treatment of infected flocks is difficult since even long-term antibiotic therapy may result in subclinical carriers. Therefore, during an outbreak, additional sanitary and hygienic measures have to be taken. Vaccination with bacterin might also be useful since experimental studies. Uyttebroek et al. [21] demonstrated a significantly lower faecal excretion of Salmonella microorganisms following infection of vaccinated pigeons. Recently, a newly developed Salmonella bacterin has been marketed. Duchatel et al. [22] following intramuscular challenge with $S$. Typhimurium demonstrated a significant decrease of mortality in pigeons vaccinated with bacterin vaccine.

The present work aimed to prepare an experimental combined inactivated oil adjuvanted vaccine of PPMV-1 and $S$. Typhimurium. In addition, evaluation of the immunizing and protective efficacy of such preparation through monitoring of the humoral immune response against both diseases and measuring protective percentage through vaccination/ challenge assay were carried out.

\section{Material and Methods}

\section{Pigeons}

A total of ninety, 4 weeks aged pigeons were obtained from a commercial pigeonbreeding centre and kept under strict hygienic measures of rearing and feeding. Cloacal swabs and blood samples were collected from pigeon to confirm that they were free from both $S$. Typhimurium and PPMV-1.

\section{Vaccinal strains}

Salmonella Typhimurium local isolate

Local isolate of $S$. Typhimurium (pigeon isolate) was obtained from Central Laboratory for Evaluation of Veterinary Biologics (CLEVB). This strain was identified morphologically as well as biochemically and serologically following the method adapted by Nagraja et al. [23].

\section{Pigeon paramyxovirus type 1 (PPMV-1) virus}

Local field strain was kindly obtained from Central Laboratory for Evaluation of Veterinary Biologics (CLEVB). The strain was identified clinically and pathologically and titrated in chicken eggs.

\section{Vaccine preparation}

$S$. Typhimurium was grown on tryptic soya agar (Difco) for $24 \mathrm{~h}$ at $37^{\circ} \mathrm{C}$. Bacteria were harvested and the concentration of bacterial suspension was adjusted to contain $10^{9}$ organisms/dose in normal saline. The purity of the culture was examined by inoculation onto brilliant green agar plat (Difco). The bacterial culture was inactivated by adding $0.3 \%$ formalin with agitation then the inactivation was ensured by plating onto nutrient agar and incubation at $37 \mathrm{C}^{\circ}$ for $24 \mathrm{~h}$ [21].

The local pigeon isolate of PPMV-1 was inoculated into the allantoic sac of each 10days-old SPF embryonated chicken eggs and incubated at $37^{\circ} \mathrm{C}$. Embryos dying during 48-72 hours after inoculation were chilled until harvesting time. The collected fluid was titrated and used for vaccine preparation after justification of the titer to be $10^{9} /$ dose then inactivation by formalin $0.1 \%$ was carried out as described by Allan et al. [24].

According to the manufacturer (SEPPIC France Company), Montanide ISA 206 was added as equal parts of an aqueous and oil phase $\mathrm{v} / \mathrm{v}$ and mixed thoroughly to prepare combined bacterin $S$. Typhimurium $10^{9}$ CFU/dose and PPMV-1 $10^{9}$ EID50/dose. 


\section{Experimental Design}

Ninety pigeons were divided into 3 groups and treated as follows: Group (I): comprised 40 pigeons vaccinated with $0.5 \mathrm{~mL}$ S.C of the locally prepared Montanide ISA 206 combined bacterin $S$. Typhimurium $10^{9} \mathrm{CFU} /$ dose and PPMV-1 was $10^{9} /$ dose and all birds received a booster dose $(0.5 \mathrm{~mL})$ S.C three weeks later. Group (II): comprised 40 pigeons kept as control unvaccinated group. Group (III): comprised 10 pigeons inoculated with the double field dose S.C from the prepared vaccine to perform the safety test.

Three weeks post boostring, pigeons of groups (I and II) were divided into two subgroups ( $a$ and $b$ ) and challenged with virulent strain of $S$. Typhimurium and PPMV-1. Blood samples were obtained from groups (I and II) weekly post vaccination up to 6 weeks to follow up the levels of induced immunity using $\mathrm{HI}$ and microplate agglutination test.

Quality control of prepared combined inactivated PPMV-1 and S. Typhimurium vaccine

\section{Sterility tests}

The prepared vaccine was tested for freedom from contamination with bacteria, fungi and mycoplasma according to OIE Manual [25].

\section{Safety test}

Ten birds were inoculated with the double field dose S.C from the prepared vaccine and kept under daily observation for 14 days according to OIE Manual [25].

\section{Potency tests}

Protection rates of the prepared Montanide ISA 206 combined inactivated PPMV-1 and $S$. Typhimurium vaccine were carried out primarily by using the vaccination/challenge test. Also, sero-evaluation of the immune response was adopted, where serum samples were collected from vaccinated pigeons and tested by microagglutination test ( $S$. Typhimurium) and haemagglutation inhibition test (PPMV-1).

\section{Microplate agglutination test}

The test was used to evaluate the humoral immune response developed against $S$. Typhimurium in the vaccinated pigeons using sera collected post vaccination according to OIE Manual [25].

II. Haemagglutation inhibition (HI) test

The test was carried out to evaluate the humoral immune response obtained aginst PPMV-1 [26,27].

\section{Challenge test}

Vaccinated and unvaccinated pigeons were evaluated through vaccination/challenge test by using virulent strain of $S$. Typhimurium in a concentration of $5 \times 10^{7} \mathrm{CFU/} \mathrm{pigeon}[22,25]$ and by using virulent strain of PPMV-1 with $\mathrm{EID}_{50}$ of $10^{6} / \mathrm{mL}$ [28]. The virulent strains were obtained from CLEVB and inoculated as $0.5 \mathrm{~mL} / \mathrm{bird}$ intramuscularly three weeks post boostering. Birds were kept under observation three weeks post challenge for recording mortality and disease symptoms.

\section{Results and Discussion}

Prevention of infectious diseases has become an important and significant aspect of pigeon management, though if the infectious diseases are not controlled the birds will perform poorly and will be unproductive. PPMV-1 cause serious neurological and renal disease in pigeons, and can easily be prevented by vaccination [9]. Another significant disease condition in pigeons is Salmonella infection (Paratyphoid) which is one of the most frustrating and difficult problems encountered in pigeons and often occur in the best managed lofts. Because of the dormant nature of the Salmonella spp., apparently healthy birds can serve as carriers; it often causes disease during times of stress and in young birds raised by carrier parents. This bacterium, as described earlier, has already developed significant antibiotic resistance, therefore, vaccination would be strongly recommended. Many trials were carried out using different strains of NDV vaccines to protect pigeons against 
paramyxovirus infection. Greuel et al. [29] and Luethgen [30] found that Hitchner B1 and LaSota strains of NDV vaccines could not protect pigeons against the paramyxovirus infection, while, Fritzsch et al. [31] concluded that homologous vaccine is in need to provide complete protection for pigeons against the disease.

Quality control of the prepared vaccine revealed that the pigeon group inoculated with double field dose (safety test) of the prepared vaccine remained healthy all over the experimental period proving that the vaccine is safe for pigeons. Also, when the same vaccine was inoculated onto the different types of bacterial, fungal and mycoplasma media following OIE Manual [25], to detect its freedom from any contaminants, the prepared vaccine showed no growth for any of these contaminants.

Table 1: Mean titer of microagglutination test against $S$. Typhimurium post vaccination in pigeon vaccinated with locally prepared combined inactivated Montanide ISA $206 S$. Typhimurium and PPMV-1 vaccine

\begin{tabular}{|c|c|c|c|c|c|c|c|}
\hline \multirow{2}{*}{$\begin{array}{c}\text { 总 } \\
\text { vaccination }\end{array}$} & \multicolumn{5}{|c|}{ Titer / Weeks post vaccination } \\
\cline { 2 - 8 } & & $\mathbf{1}^{\text {st }} \mathbf{w}$ & $\mathbf{2}^{\text {nd }} \mathbf{w}$ & $\mathbf{3}^{\text {rd }} \mathbf{w}$ & $\mathbf{1}^{\text {st }} \mathbf{w} \mathbf{P b}$ & $\mathbf{2}^{\text {nd }} \mathbf{w} \mathbf{P b}$ & $\mathbf{3}^{\text {rd }} \mathbf{w} \mathbf{P b}$ \\
\hline Group I & 0 & 16 & 32 & 64 & 128 & 256 & 256 \\
\hline Group II & 0 & 0 & 0 & 0 & 0 & 0 & 0 \\
\hline
\end{tabular}

Group-1 vaccinated with locally prepared combined inactivated Montanide ISA 206 S. Typhimurium and PPMV-1 vaccine, Group-II unvaccinated pigeons (control), $\mathrm{Pb}=$ Post boostering.

Regarding the humoral antibody responses, they were checked as shown in Table (1). The level of mean titer of microagglutination test against $S$. Typhimurium post vaccination in pigeons with locally prepared combined inactivated Montanide ISA $206 \mathrm{~S}$.
Typhimurium and PPMV-1 vaccine showed marked increase from 0 titer pre-vaccination to 64 three weeks post the $1^{\text {st }}$ dose of vaccination and reached to maximum 256 at the $2^{\text {nd }}$ week post boostering, while, unvaccinated pigeons remained sero-negative.

Table 2: Mean serum HI antibody titers $\left(\log _{2}\right)$ of PPMV-1 in pigeons vaccinated with locally prepared combined inactivated Montanide ISA 206 . Typhimurium and PPMV-1 vaccine

\begin{tabular}{|c|c|c|c|c|c|c|}
\hline \multirow{2}{*}{ Groups } & \multicolumn{6}{|c|}{ Titer / Weeks post vaccination } \\
\cline { 2 - 7 } & $\mathbf{1}^{\text {st }} \mathbf{w}$ & $\mathbf{2}^{\text {nd }} \mathbf{w}$ & $\mathbf{3}^{\text {rd }} \mathbf{w}$ & $\mathbf{1}^{\text {st }} \mathbf{P b}$ & $\mathbf{2}^{\text {nd }} \mathbf{w} \mathbf{P b}$ & $\mathbf{3}^{\text {rd }} \mathbf{w} \mathbf{P b}$ \\
\hline Group I & 3.1 & 4.4 & 7.0 & 7.2 & 8.0 & 8.0 \\
\hline Group II & $-\mathrm{ve}$ & $-\mathrm{ve}$ & $-\mathrm{ve}$ & $-\mathrm{ve}$ & $-\mathrm{ve}$ & $-\mathrm{ve}$ \\
\hline
\end{tabular}

Group-1 vaccinated with locally prepared combined inactivated Montanide ISA 206 S.Typhimrium and PPMV-1 vaccine, Group-I1 unvaccinated pigeons (control), $\mathrm{Pb}=$ Post boostering.

The evaluation of humoral immune response of pigeon against paramyxovirus after administration of the prepared vaccine using HI test is shown in Table (2). It was found that the vaccinated pigeons exhibited detectable antibodies by the first week post vaccination (3.1) and markedly increased till the end of the experiment $\left(8.0 \log _{2}\right)$, while unvaccinated pigeons remained sero-negative. These results come in parallel with those reported by Wawizkiewicz et al. [32] where oil emulsion PPMV-1 vaccine gave higher antibody response of a mean $8.9 \log _{2} \mathrm{HI}$ titer at the third week after the second vaccination. 
Table 3: Protective percentage of pigeon vaccinated with locally prepared combined inactivated Montanide ISA 206 of $S$. Typhimurium and PPMV-1 vaccine challenged with virulent strain of both $S$. Typhimurium and PPMV-1

\begin{tabular}{|c|c|c|c|c|c|}
\hline \multicolumn{2}{|c|}{ Group } & \multirow{2}{*}{ Mortality } & \multicolumn{2}{c|}{ Survival } & \multirow{2}{*}{ Protection \% } \\
\cline { 4 - 6 } & & With lesions & Without lesions & \multirow{2}{*}{$100 \%$} \\
\hline \multirow{2}{*}{ Group I } & a & $0 / 20$ & $0 / 20$ & $20 / 20$ & $90 \%$ \\
\cline { 2 - 6 } & b & $0 / 20$ & $2 / 20$ & $18 / 20$ & $10 \%$ \\
\hline \multirow{2}{*}{ Group II } & a & $8 / 20$ & $10 / 20$ & $2 / 20$ & $20 \%$ \\
\cline { 2 - 6 } & b & $5 / 20$ & $11 / 20$ & $4 / 20$ & \\
\hline
\end{tabular}

Group-1a: Vaccinated Pigeons with prepared combined vaccine and challenged with virulent strain of PPMV-1, Group-1b: Vaccinated pigeons with prepared combined vaccine and challenged with virulent strain of $S$. Typhimurium. Group-IIa: unvaccinated pigeons (control) challenged with virulent strain of PPMV-1, Group-IIb: unvaccinated pigeons (control) challenged with virulent strain of S.Typhimurium.

Concerning the protection percentage of vaccinated pigeons post challenge against Paramyxovirus and $S$. Typhimurium, the vaccine provided $100 \%$ protection against the homologous PPMV-1 and $90 \%$ against $S$. Typhimurium (group Ia and group Ib, respectively). At the same time and under the same circumstances, the unvaccinated control group showed $10 \%$ and $20 \%$ protection against both virulent PPMV-1 and $S$. Typhimurium, respectively (Table 3 ). Our results were consistent with Duchatel et al. [22] who used intramuscular challenge and observed a clear reduction in post-inoculation morbidity and mortality of Salmonella vaccinated pigeons. There is an association between the presence of high titer of antibodies and protection against $S$. Typhimurium and PPMV-1 infection.

In the present study, a protective effect in the vaccinated pigeons was consistently observed. The locally prepared combined inactivated Montanide ISA 206 of $S$. Typhimurium and PPMV-1 vaccine was safe and effective. This was in agreement with Barrow [33] who reported that inactivated vaccine of avian salmonellosis had protection against Salmonella infection. Also, Amer et al. [28] found that pigeon paramyxo vaccine provided $100 \%$ protection against the homologous pigeon paramyxo virus and only $10 \%$ protection in unvaccinated pigeon.

\section{Conclusion}

It could be concluded that the prepared vaccine could be used for protection against
PPMV-1 and $S$. Typhimurium infection under field condition as safe and potent vaccine.

\section{Conflict of interest}

The authors declare no conflict of interest.

\section{References}

[1] Vindevogal, H. and Duchatel, J.P. (1993): Paramyxovirus type 1 infectionin pigeons. Virus infections of birds, Chapter 24: 363 374.

[2]Mohammed, M.A.; Sokkar, S.M.; Yousif, Y.I.; Saad, F. and Bastami, M. (1980): Contagious paralysis of pigeons: A preliminary investigation on the occurrence of the disease in Egypt. J Egypt Vet Med Assoc, 40 (1): 45 -51.

[3]Ahmed, H.N. and Sabri, I. (1969): Isolation of Newcastle disease virus from pigeons infected with pigeon pox. J Vet Sci UAR, 6: $47-53$.

[4]Shakal, M.A. (1989): Studies on paramyxovirus infection in pigeons in Egypt. PhD thesis, Poultry Diseases, Faculty of Veterinary Medicine, Cairo University.

[5]Abou Hashem, N.A. (1993): Studies on some paramyxovirus infections in pigeons. MVSc thesis, Department of Poultry and Fish Diseases, Faculty of Veterinary Medicine, Zagazig University.

[6]Awad, M.H. (1992): Studies on the development of Newcastle disease killed vaccine. MVSc thesis, Microbiology, 
Faculty of Veterinary Medicine, Cairo University.

[7]Alexander, D.J. (2011): Newcastle disease in the European Union 2000 to 2009. Avian Pathol, 40(6): 547-558.

[8]Aldous, E.W.; Mynn, J.K.; Banks, J. and Alexander, D.J. (2003): A molecular epidemiological study of avian paramyxovirustype 1 (Newcastle disease virus) isolates by phylogenetic analysis of a partial nucleotide sequence of the fusion proteingene. Avian Pathol. 32(3): 239-356.

[9]Alexander, D.J.; Russell P.H.; Parsons, G.; Elzein, E.M.; Ballouh, A.; Cernik, K.; Engstrom, B.; Fevereiro, M.; Fleury, H.J.; Guittet, M,; Kaleta, E.F.; Kihm, U.; Kosters, J.; Lomniczi, B.; Meister, J.; Meulemans, G,; Nerome, K.; Petek, M.; Pokomunski, S.; Polten, B.; Prip, M.; Ritchter, R.; Saghy, E.; Samberg, Y.; Spanoghe, L. and Tumova, B. (1985): Antigenic and biological characterization of avian paramyxovirus type 1 isolates from pigeons - an international collaborative study. Avian Pathol, 14: 365-376.

[10]Marlier, D. and Vindevogel, H. (2006): Viral infections in pigeons. Vet J, 172: 4051.

[11]El-Zanaty, K.; Abd El-Motilib, T.Y.; Seifedin, M. and Solem, B. (1992): Vaccination against paramyxovirus type 1. Assiut Vet Med J, 26 (52):265- 271.

[12]Hassan, E.A. (1997): Some trials for vaccine production against paramyxovirus infection in pigeons. MVSc thesis, Virology, Faculty of Veterinary Medicine, Alexandria University.

[13]Dumitrache, D. (2013): Salmonellosis and Mycoplasmosis in pigeons. J Appl Bacteriol, 78 (1): 11-3.

[14]Tauxe, R.V. (1991): Salmonella: a post modem pathogen. J Food Protect, 54 (7): 563-568.

[15]Casanovas, L.; Simon, D.E.; Ferrer, M.; Arques, M.J. and Monzón, G. (1995): Intestinal carriage of campylobacters, salmonellas, yersinias and listerias in pigeons in the city Barcelona. J Appl Bacteriol, 78 (1): 11-13.

[16]Adesiyun, A.A.; Seepersadsingh, N.; Inder, L. and Caesar, K. (1998): Some bacterial enteropathogens in wildlife and racing pigeons from Trinidad. J Wildl Dis, 34(1):73-80.

[17]Toro, H.; Saucedo, C.; Borie, C.; Gough, R. and Alcaíno, H. (1999): Health status of free-living pigeons in the city of Santiago. Avian Pathol, 28 (6): 619-23

[18]González-Acuña, D.; Silva, F.G.; Moreno, L.S.; Cerda, F.L.; Donoso, S.E.; Cabello, J.C. and López, J.M. (2007): Detección de algunosagenteszoonóticos en la Palomadoméstica (Columba livia) en la ciudad de Chillán, Chile. Rev Chil Infectol, 24 (3): 199-203.

[19]Sousa, E.; BerchieriJúnior, A.; Pinto, A.A.; Machado, R.Z.; Carrasco, A.O.T.; Marciano, J.A. and Werther, K. (2010): Prevalence of Salmonella spp. antibodies to Toxoplasma gondii, and Newcastle disease virus in feral pigeons (Columba livia) in the city of Jaboticabal, Brazil. J Zoo Wildl Med, 41 (4): 603-607.

[20]Ammar, A., Sultan, H., El-Sayed, I., Yousef, S. and Mamdouh R. (2014): Seroprevalence of salmonellosis among pigeon and its surrounding environment and isolation of Salmonella species. Int $\mathbf{J}$ Sci Res, 3 (9): 1856-1862.

[21]Uyttebroek, E., Devriese, L.A., Gevaert, D., Ducatelle, R., Nelis, J. and Haesebrouck, F. (1991): Protective effects of vaccines against experimental salmonellosis in racing pigeons. Vet Rec, 128(7): 152-153.

[22]Duchatel, J.P.; De Ree, J.M. and Vindevogel, H. (1998): Essais de vaccination de pigeons contre la paratyphose au moyen de vaccins inactiv'es en suspension aqueuse: d'etermination de la dose vaccinale. Ann Méd Vét, 142(1): 35-38. 
[23]Nagraja, K.V.; Kim, C.J.; Kumer, M.C. and Pomeroy, B.S. (1991): Vaccination a feasible approach for the control of Salmonella. Colonization control of human bacterial pathogens in poultry. LC Blankenship, JS Bailey, NA Cox, NJ Stern, and R. J. Meinersmann, eds. Academic Press, New York, pp.243-258.

[24]Allan, W.H.; Lancaster, J.E. and Toth, B. (1973): The production and use of Newcastle disease vaccines. Foot and Agriculture Organization, Rome, Italy. Animal Health Report, London.

[25]OIE Manual (2012): Manual of standards of diagnostic test and vaccines for terrestrial animals' safety test.

[26]Anon, A. (1971): Methods for examination of biologics and for identifying avian pathogens. National Academy of Science, Washington D.C., p.83-87.

[27]Munir, S.; Hussain, M.; Farooq, U.; Jamal, Z.Q.; Afreen, M.; Bano, K. and Anees, M. (2012): Quantification of antibodies against poultry haemagglutinating viruses by haemagglutination inhibition test in Lahore. Afr J Microbiol Res, 6(21): 46144619.
[28]Amer, M.I.S.; El-Bagoury, G.F. and Khodeir, M.H. (2013): Evaluation of the immune response of pigeons to Newcastle disease and pigeon paramyxo virus vaccines. Benha Vet Med J, 24(2):148156.

[29]Greuel, E.; Robl, R. and Dicks, J. (1973): Untersuchungen zur epidemiologic der atypischen cefluigelpest bei tauben. 3 . Internat. Kongr. WVPA, Munchen, 450 453.

[30]Luethgen, W. (1975): Versuche zur impf prophylaxe der taube (Columba livia dom.). BMTW, 88: $27-39$.

[31]Fritzsch, K.; Kabeta, E.F.; Ruger, R. and Meister, J. (1984): Simultaneous vaccination of carrier pigeons against paramyxovirus-1 infection and pigeon pox. Prakt Tierarzt, 65 (8): 676 - 678 .

[32]Wawrzkiewicz J.; Pochodyla, A.; Kania, W.; Grzeda, T.; Laskarzewska, J.; Michas, I. and Gasiorczyk A. (1991): PM-VAC, a vaccine against pigeon paramyxoviruses. Med Weter, 47 (3): 108 - 110.

[33]Barrow, P.A. (1991): Experimental infection of chickens with Salmonella enteritidis. Avian Pathol, 20 (1): 145-53.

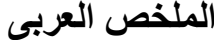 \\ كفاءة استخدام لقاح تجريبى ثنائى مثبط من السالمونيلا تيفيميوريم و فيروس البار اميكزو في الحمام \\ عفاف احمد خضر'، انهار عبد المعطى عبد اللطيف' ، محمود لطفى سيد' ، محمد عبد الخالق عبدربه' ، نور هان ناجى' ، امينة

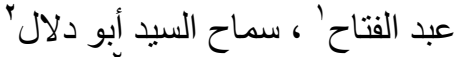

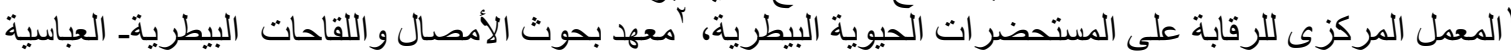

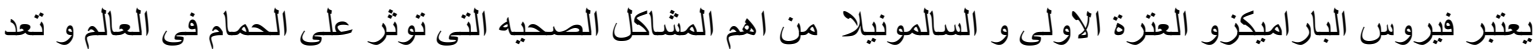

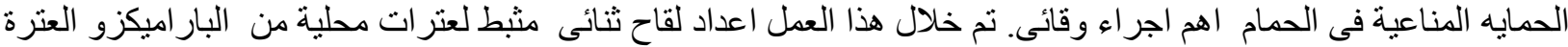

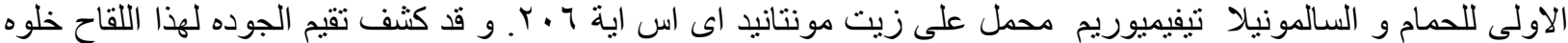

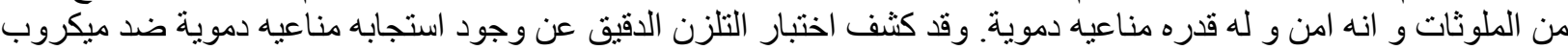

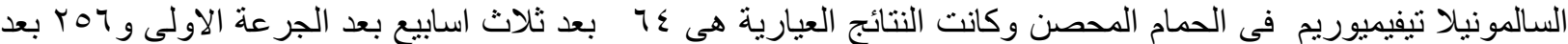

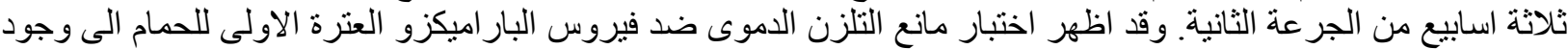

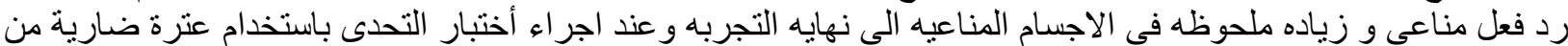

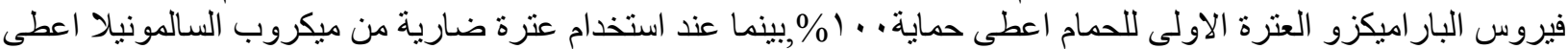

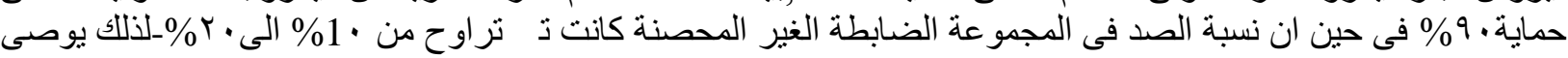
باستخدام هذا اللقاح لانه لقاح امن و يحقق مستوى المناعة الدموية المطلوبة للحماية ضد الند هذه الامر اض. 